listening to his remarks by the bedside were frequently to be found some of his old house physicians who had returned to brush up their work. In the days when I was his house physician he was especially enthusiastic upon the use of the ice-bag for 'pneumonia. At the beginning of our six months' residence few of his house physicians were so sanguine in this direction as our master, but when our time of office had expired most of us were converted to his views. He used to insist that the first thing to be done was to place hot-water bottles to the feet of the patient and then to apply ice-bags not only to the dull area, but to the entire lung affected. There is no doubt that under this treatment the area of dullness receded sometimes in a remarkable manner, and if one could not state with certainty that the treatment aborted the disease (though at times it appeared to do so) it gave great relief to the patient.

Dr. Lees was, perhaps, best seen in his systematic lectures, which always gave evidence of careful preparation and attracted large attendances. His sterling and upright character will always remain as a bright example to those who were associated with him. I am, Sir, yours faithfully,

City of London Mental Hospital, Dartford. R. H. STEEN.

TRENCH FROST-BITE.

To the Editor of THE LANCET.

SIR,--In the "Practical Considerations for Prevention" suggested by the authors of the paper on the Pathology of Trench Frost-bite ${ }^{1}$ there is an omission which seems to me important. No recommendation is made for the provision of high rubber boots and thigh wader attachments. If the men were allowed to wear these there is no doubt that the cases of frost-bite would be few, and the other preventive measures suggested would be unnecessary. Leather boots, leggings, extra clothing, and vaseline to the feet are all useless when once they become wet, and with water near freez. ing point 36 to 48 hours' exposure is quite enough to produce frost-bite. Men who have gone for several days on ski-ing expeditions with the ordinary ski-boots (which are saturated with grease and made as waterproof as possible) will recall that at the end of a day's march the leather is sodden, and unless the boots are dried near the convenient hotel radiators, the next day they begin to let the melting snow in. That happens in running through dry, crisp snow; standing in icy water continuously, the wet-resistance of the leather would be less.

I would suggest: 1. Two pairs of easy fitting socks. 2. Pliable leather boots with plenty of toe room. (It is most important that the foot be not cramped and that the toes can be easily moved.) 3. High rubber boots, coming well up to the knee. 4. For men going into trenches where it is known that the water is high, impermeable rubber-fabric waders and breeches combined. If the men start out with warm feet thus clothed, and are encouraged to move the feet and toes, they will keep warm unless leakage of water occurs into the boot. Nothing but rubber is of any use. If the rubber boots are impracticable, then a stout rubber-treated canvas stocking and thigh-piece could be worn over two pairs of socks and inside the ordinary soldier's boot, care being taken that the boot is extra large and that ankles and toes are free from constriction. I am, Sir, yours faithfully,

Darley Dale, Matlock, Sept. 14th, 1915. W. CECIL SHARPE.

1 The LaNCeT, Sept. 11th, 1915, p. 595.

\section{A GREEN BACKGROUND FOR THE} OPERATION AREA.

To the Editor of THE LANCET.

SIR,-It has long been the custom of surgeons to use white sterile towels or sheets around the area upon which an operation is to be done. There are many disadvantages in the use of white. A large expanse of white, especially when the sun is shining, is wearisome to the eye and causes fatigue, and it detracts from the value of the light upon and within the wound. It is not sufficiently realised that good illumination is not needed, except upon the part which is concerned in the operation. Light should be concentrated upon the wound and not widely diffused. For the last two and a half years I have used towels and sheets of green colour instead of white. Green is a restful colour, offers no sharp contrast to the colours of the wound surfaces, and allows ligatures and sutures to be clearly seen against it. I have tried black towels, but the change from black to other colours in an operation theatre is sudden and trying, and ligatures do not stand out clearly against such a background. I have painted the walls of my operation theatre green, and have a green coloured material on the floor. The great relief to the eyes which results from the use of a green material round the wound is remarkable. The ordinary green " casement cloth" from which my towels and sheets are made is of good colour, retains its colour on washing and sterilising, is easily obtained, and is cheap.

I am, Sir, yours faithfully,

Leeds, Sept. 9th, 1915.

Berkeley Moynihan.

\section{THE CAUSE OF ENLARGED TONSILS.}

\section{To the Editor of THE LANCET.}

SIR,-In his Hunterian lecture in THE LANCET of May 22nd Mr. F. C. Pybus does not overlook this very common ailment in his exhaustive account of infections of the tonsils. Although he rightly describes the condition as being the result of repeated slight attacks of tonsillitis, I do not think that he hits the mark when he speaks of measures of prevention. He recommends good milk (probably with tuberculosis in fear), a plain, wholesome diet and cleaner air, but says nothing at all about cleaner water. In a disease that is so common and slight, possible contributory causes are naturally plentiful and inconspicuous; but I believe that the one potent factor is impure water. I have observed for very many years, both in London and Australia, that children who develop and suffer from enlarged tonsils habitually drink unfiltered and unboiled tap-water. This is almost, if not quite, invariably the case in my experience. I always make the inquiry when I meet with such a case, and I cannot remember receiving a negative answer; further than this, I am usually told that the child is specially addicted to drinking from the tap. This is probably due to the dryness and thirst provoked by the frequent febrile condition of slight tonsillitis; and thus the morbid condition is aggravated. When I have succeeded in getting plain tap-water improved by being filtered or boiled, I am quite sure that the patient's condition has improved also and that attacks of tonsillitis have been less frequent. If $I$ am right in my view, it ought to be a simple matter in very many cases to prevent the disease I should like to know the opinion of other members 
of the profession on the subject. As far as I know, this mode of causation is not specially mentioned in the text-books.

I look on the tonsils as a filter to prevent certain noxious matters entering the system by way of the mouth. When such noxious matters are in excess, the filter becomes clogged and is unable to cope with the material and in consequence becomes inflamed and morbidly hypertrophied.

I am, Sir, yours faithfully,

F. Lucas BenhaM, M.D., M.R.C.P. Lond. Exeter, South Australia, July 21st, 1915.

\section{MEDICAL ATTENDANCE AT NIGHT. To the Editor of THE LANCET.}

SIR,-I am glad you have again drawn attention to this matter, as it is a grave defect in the organisation of the profession for attendance upon the public. From time to time some scandal occurs, and strong but often quite unfair comments are made upon the conduct of some medical practitioner who possibly for perfectly good reasons was unable to attend the emergency call.

I have previously drawn attention to the scheme which apparently works quite well in Paris (see Medical Ethics, second edition, p. 87). In that city doctors who are willing to undertake night work inscribe their names in a list kept at the police office of each district, and are then liable to be called upon by any person provided with an order from the police office, which is kept open all night and to which applicants in need of medical assistance can go. The doctors are paid by funds raised partly by charity and partly from public money; this last is essential, as it is monstrously unfair to expect that doctors should attend night calls without a reasonable prospect of being paid for their trouble.

I am, Sir, yours faithfully,

Birmingham, Sept. 13th, $1915 . \quad$ ROBERT SAUNDBY.

\section{THE VALUE OF PROLONGED REST IN THE TREATMENT OF HEART DISEASE}

\section{IN THE YOUNG.}

To the Editor of THE LANCET.

SIR,-I have read with much interest Dr. Guy Barton's article on the above subject which appeared in THE LANCET of Sept. 11th. I note that he makes no mention of treatment by baths and exercises, commonly known as the "Nauheim" treatment. I have used this treatment in cardiac cases in children of from five vears of age upwards, and it is my experience that the "Nauheim" treatment, combined with rest, is productive of a much more rapid and complete return to health in cases of children suffering from the results of rheumatic myocarditis and endocarditis than is the case if rest is the only treatment. In cases of valvular disease, where there is good compensation and no cardiac dilatation, the treatment is not necessary, but when any cardiac dilatation is present it produces results which cannot be obtained by any other methods. As the treatment can be given in England with results as satisfactory as those obtained at Nauheim, I should be interested to know if Dr. Barton has used it, and, if so, whether he has given the "still" baths in the first half of the course. I am, Sir, yours faithfully, LESLIE ThORNE THORNE.
MEDICAL STUDENTS AND COMBATANT COMMISSIONS.

To the Editor of THE LANCET.

SIR,-Lord Kitchener's opinion that junior medical students should not be discouraged from taking combatant commissions clears the air for those who still have doubts. It is obvious that junior students, as such, cannot be of use to their country during the war; while manifestly it would be a pity that the study of medicine should be regarded as a bomb-proof shelter where lack of patriotism could be euphemistically described as doing better work at home. Logically it could be shown that everyone is better at home; but alas! it would be a German home. In times of war there is always an apparent dearth of doctors, and this must be more marked in Germany than with us; in times of peace this soon rights itself. The scarcity of medical residents for hospitals before the war is no index of the shortage of numbers in the profession, it is merely evidence that the medical curriculum is too long.

I am, Sir, yours faithfully,

Formby, Sept. 4th, 1915. Arthur C. WILson.

\section{THE PRESENT INCIDENCE OF GLAUCOMA.} To the Editor of THE LANCET.

SIR,-During the past three months I have seen four times as many fresh cases of glaucoma as in the corresponding period of any former year. In a large proportion the patients so affected have relations serving in the war. It would be interest. ing to know if others of your readers have remarked the same occurrence.

I am, Sir, yours faithfully,

Wimpole-street, W., August 29th, 1915. KenNeTH CAMPBELL.

\section{A "NEW SIGN" IN PULMONARY DIAGNOSIS. \\ To the Editor of THE LANCET.}

SIR,-The mid-dorsal strip of symmetrical dullness between the fifth and seventh spinous levels, which has been identified by Dr. Clive Riviere, is of great interest as a new departure for study. The practical use which he claims for it in the early diagnosis of pulmonary tubercle or of its threatenings, is enough to earn for it a thorough investigation. At the least, this sign cannot fail to be of permanent value as a substantial basis for the study of the so-called "pulmonary reflex" to which he refers as a part factor in its production. The somewhat immature nature of the evidence which has thus gained a free pass into an argument of fact is not the least important feature in the main proposition, and may justify some brief comment.

Abrams's theory of the occurrence of reflex fluctuations in the local ventilation of the lung is an undeniably suggestive addition to our vague conceptions concerning the intrapulmonary distribution of air. Yet we should not overlook the coarser mechanisms which govern the pulmonary air-charge as a whole, and also the varying local air-charge. Their consideration is nowhere so essential as for our interpretation of the results of any "mechanical" interference, such as blows or local pressures over the thoracic surface. Bones, cartilages, and fibrous tissues are the actual moving levers in respiration; but they are entirely passive 